PREPARED FOR THE U.S. DEPARTMENT OF ENERGY, UNDER CONTRACT DE-AC02-76CH03073

PPPL-3851

PPPL-3851

UC-70

Wave Driven Fast Ion Loss

in the National Spherical Torus Experiment

by

E.D. Fredrickson, C.Z. Cheng, D. Darrow, G. Fu, N.N. Gorelenkov, G. Kramer, S.S. Medley, J. Menard, L. Roquemore, D. Stutman, and R.B. White

August 2003
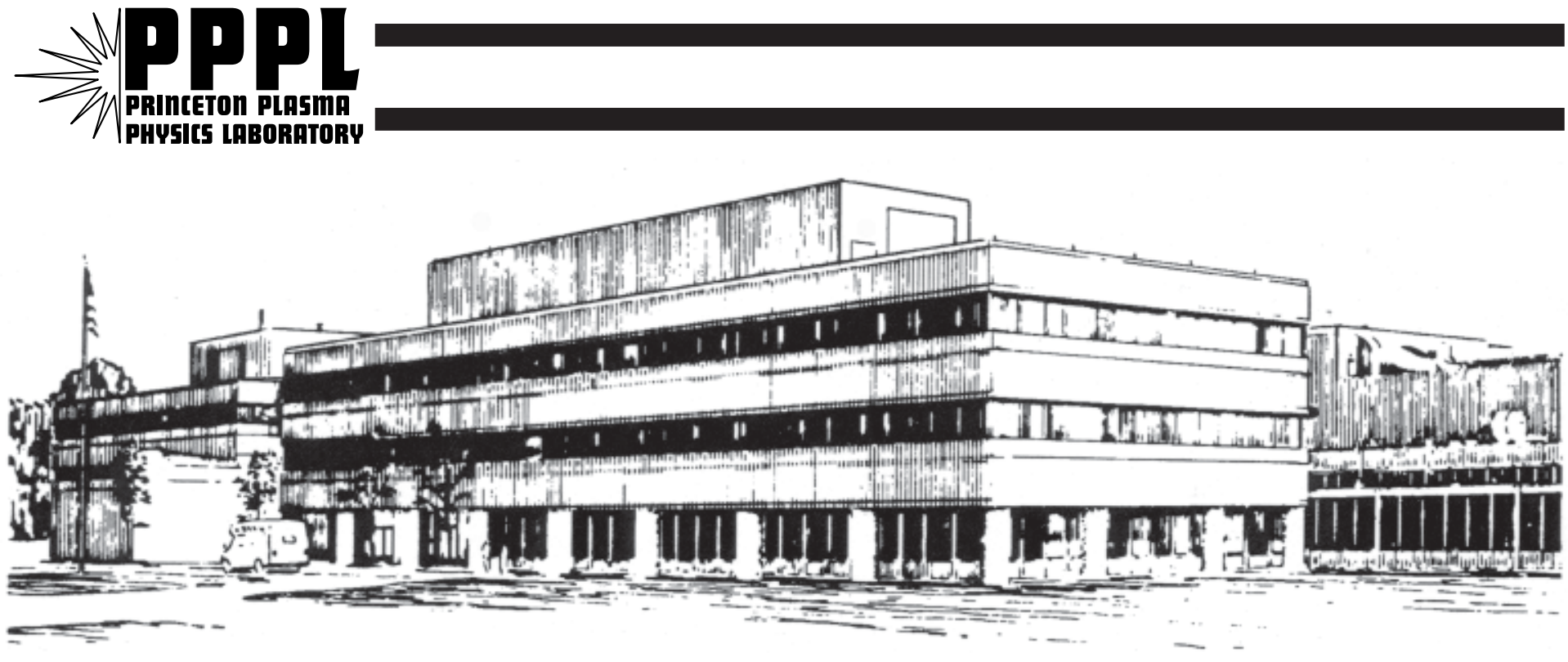

PRINCETON PLASMA PHYSICS LABORATORY PRINCETON UNIVERSITY, PRINCETON, NEW JERSEY 


\section{PPPL Reports Disclaimer}

This report was prepared as an account of work sponsored by an agency of the United States Government. Neither the United States Government nor any agency thereof, nor any of their employees, makes any warranty, express or implied, or assumes any legal liability or responsibility for the accuracy, completeness, or usefulness of any information, apparatus, product, or process disclosed, or represents that its use would not infringe privately owned rights. Reference herein to any specific commercial product, process, or service by trade name, trademark, manufacturer, or otherwise, does not necessarily constitute or imply its endorsement, recommendation, or favoring by the United States Government or any agency thereof. The views and opinions of authors expressed herein do not necessarily state or reflect those of the United States Government or any agency thereof.

\section{Availability}

This report is posted on the U.S. Department of Energy's Princeton Plasma Physics Laboratory Publications and Reports web site in Fiscal Year 2003. The home page for PPPL Reports and Publications is: http://www.pppl.gov/pub_report/

DOE and DOE Contractors can obtain copies of this report from:

U.S. Department of Energy

Office of Scientific and Technical Information

DOE Technical Information Services (DTIS)

P.O. Box 62

Oak Ridge, TN 37831

Telephone: (865) 576-8401

Fax: (865) 576-5728

Email: reports@adonis.osti.gov

This report is available to the general public from:

National Technical Information Service

U.S. Department of Commerce

5285 Port Royal Road

Springfield, VA 22161

Telephone: $1-800-553-6847$ or

(703) $605-6000$

Fax: (703) 321-8547

Internet: http://www.ntis.gov/ordering.htm 


\title{
Wave driven fast ion loss in the National Spherical Torus Experiment
}

\author{
E.D. Fredrickson, C.Z. Cheng, D. Darrow, G. Fu, \\ N.N. Gorelenkov, G Kramer, S S Medley, J. Menard, L Roquemore, \\ D. Stutman ${ }^{1}$, R. B. White \\ Princeton Plasma Physics Laboratory, Princeton, New Jersey 08543 \\ ${ }^{1}$ Johns Hopkins University, Baltimore, Maryland 21218
}

The study of fast ion instabilities in conventional aspect ratio tokamaks is motivated in large part by their potential to negatively impact the ignition threshold in fusion reactors by causing fast ion losses. Spherical tokamak's, with intrinsically low magnetic fields, are particularly susceptible to fast ion driven instabilities [1]. The 3.5 $\mathrm{MeV}$ alpha's from the D-T fusion reaction in proposed ST reactors will have velocities much higher than the Alfvén speed. The Larmor radius of the fusion alphas, normalized to the plasma size, will also be larger than for conventional aspect ratio tokamak reactors. The resulting longer wavelengths of the *AE instabilities will be more effective in driving fast ion loss. The change in magnetic topology also influences the mode structure, as in the case of the Compressional Alfvén Eigenmodes (CAE) [2] seen on NSTX [3].

The National Spherical Torus Experiment (NSTX) is a low aspect ratio $(\mathrm{R} / \mathrm{a} \approx 1.3)$ toroidal device well suited to study fast ion instabilities in a parameter regime relevant to an ST reactor. The plasma major and minor radii are $0.8 \mathrm{~m}$ and $0.65 \mathrm{~m}$ respectively. The operational parameters are up to $1.5 \mathrm{MA}$ of plasma current, 3 to $6 \mathrm{kG}$ toroidal field, central electron density is $0.5-8 \times 10^{19} / \mathrm{m}^{3}$, central electron temperature of $0.3-4 \mathrm{keV}$. The plasmas are heated with 0.5 to $6 \mathrm{MW}$ of deuterium neutral beam injection power at a voltage of up to $100 \mathrm{kV}$. The full-energy neutral beam ions in NSTX have velocities of up to four times the Alfvén velocity and normalized fast ion Larmor radii in the range 0.1 to 0.3 .

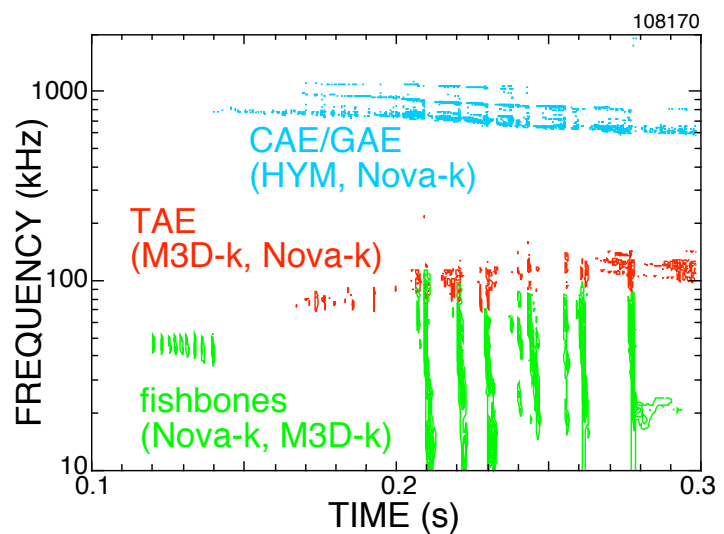

Fig.1. Spectrogram of Mirnov coil data showing the three types of fast ion driven instabilities commonly seen on NSTX. Blue contours are CAE/GAE. Red contours are TAE-like modes and green contours are fishbone-like modes. Also listed are MHD codes being employed to understand the instabilities.

Neutral beam heated plasmas in NSTX typically have a broad frequency spectrum of fast ion driven instabilities (Fig. 1). These instabilities range from a variety of fishbonelike modes with frequencies below $\approx 100$ 
$\mathrm{kHz}$ [4], through TAE-like modes in the 100 $\mathrm{kHz}$ range and $\mathrm{CAE}$ or GAE modes at frequencies up to the bandwidth limit of the Mirnov coils, $\approx 5 \mathrm{MHz}$.

In the frequency range from $0.5 \mathrm{MHz}$ to over $3 \mathrm{MHz}$, a broad spectrum of coherent instabilities is found. These modes can be quasi-continuous, bursting, and in some cases have fast frequency chirps. While many of the characteristics predicted for Compressional Alfvén Eigenmodes in ST geometry are seen in the data, Global Alfvén Eigenmodes (GAE) may also be present.

The presence of CAE activity appears to be mostly benign in NSTX. However, while there is no correlation of the appearance of CAE with degradation in performance, there are some indications that the modes do affect the transport of fast ions either in velocity or real space. Bursts of CAE activity in some cases appear to trigger the growth of other fast ion driven instabilities. Enhanced fast ion losses have been correlated with both the TAE-like and new, fishbone-like, energetic particle modes (EPM) [4].

A mode in the frequency range of the first TAE gap, whose frequency is slowing changing in time, is classified as a TAE (c.f. Fig 1, red contours). The modes which fit this description can have either a bursting or nearly constant amplitude time dependence. The toroidal mode numbers range from $n=2$ up to $n>5$. These modes are for the most part innocuous, having little or no impact on plasma performance. However, under certain special conditions the modes develop a strongly bursting character with multiple modes present. An example of such behavior is shown in Fig. 2. At each burst, up to $10 \%-15 \%$ of the most energetic fast ions are lost, as inferred from the drop in the neutron rate. Losses of fast ion are also directly observed on the Fast Lost Ion Probe (iFLIP) and losses are indirectly inferred from the D-alpha emission which shows ELM-like spikes at each fast ion loss event. The D-alpha spikes presumably indicate puffs of deuterium liberated from the carbon limiters by the impact of lost fast ions. The burst period is in the range of $5-10 \mathrm{~ms}$.

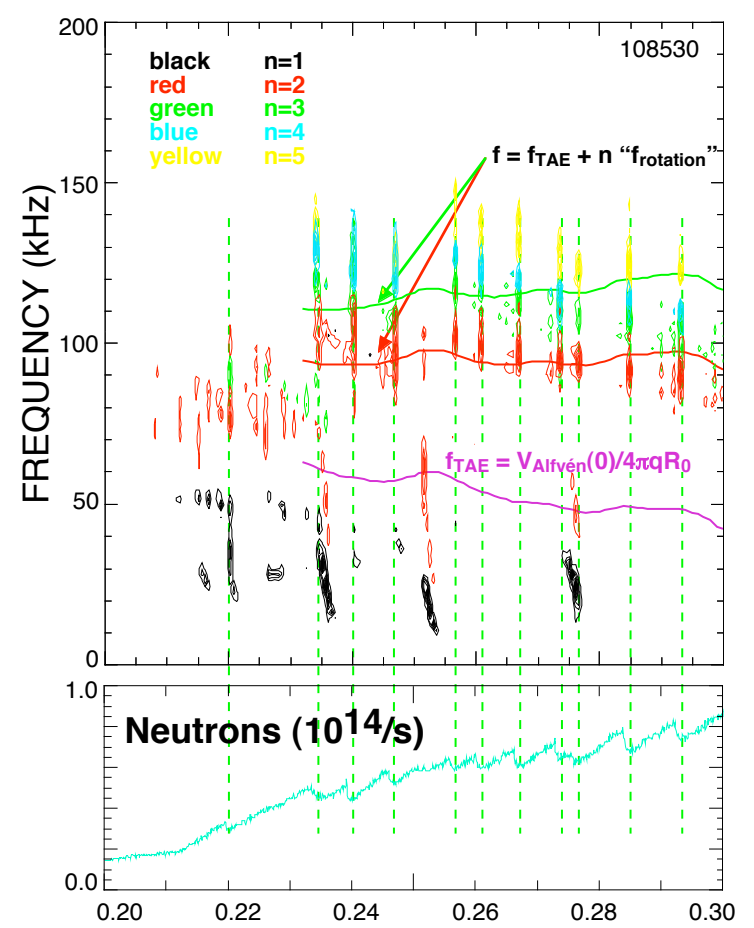

Fig.2. Spectrogram of Mirnov coil data showing bursting TAE modes between 80 and $150 \mathrm{kHz}$. Contour colors indicate toroidal mode numbers of dominant modes. Higher resolution analysis of the bursts shows the presence of many modes. The frequency-chirping modes below $70 \mathrm{kHz}$ are fishbone-like modes.

The q-profile is not directly measured, but is inferred using magnetics data with the 
EFIT equilibrium code. The bursting form of TAE modes have been seen in $\mathrm{H}$-mode plasmas where the $\mathrm{q}(0)$ is inferred to remain high, $\mathrm{q}(0) \approx 2$.

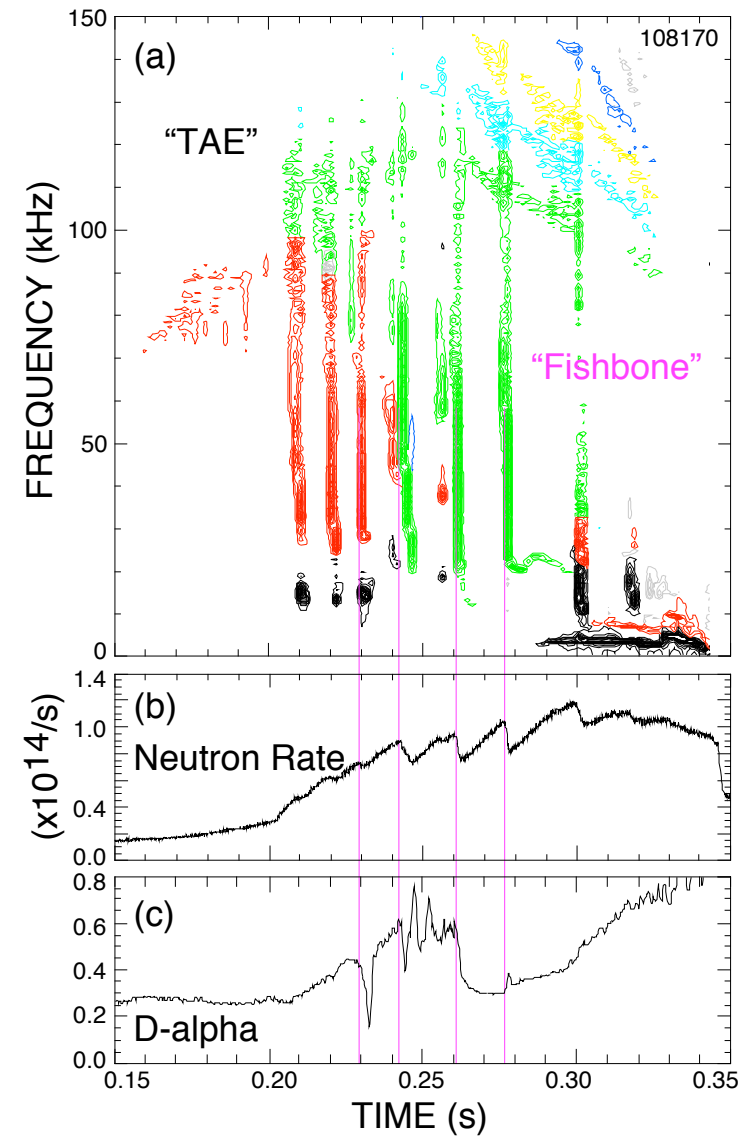

Fig. Mirnov spectrogram showing bursting, chirping modes identified as energetic particle modes, or fishbones. The contour colors indicate toroidal mode number, black is $n=1$, red is $n=2$ and green in $n=3$.

The lowest frequency energetic ion driven modes have a bursting character with strong frequency chirping. These modes have been identified as resonant Toroidal Alfvén eigenmodes (rTAE) or energetic particle modes (EPM) based on the fast frequency chirps. TAE-like modes have frequencies determined by profiles of density and plasma current; these parameters cannot be reasonably expected to change so quickly in a repetitive manner. The EPM mode frequency is set by the resonant drive condition with the fast ion distribution. This drive will change as the mode redistributes fast ions, allowing the mode frequency to change on very short timescales.

The modes are loosely classified as "fishbone modes", reflecting their superficial resemblance to the fishbones seen on conventional aspect ratio tokamaks. Fishbone-like modes are seen at frequencies of 10's of kHz (green in Fig. 1).

As can be seen in Fig. 3, these fishbone-like modes can also cause substantial burst of fast ion losses. The fast ion losses inferred from the neutron drop are most likely the highest (full) energy beam ions which produce the bulk of the fusion reactions. In Fig. 3, the first few fishbones cause almost no drop in neutron production. This could either mean that the fast ions are just redistributed within the plasma, or that the ions driving the fishbone, and thus those that are lost, are lower energy ions.

A model has been developed that in some cases a bounce resonance, rather than the precession resonance, can drive these modes [5]. The bounce resonance can involve predominantly lower energy fast ions. This observation may be important for conventional aspect ratio tokamak reactors. Previously it was assumed that as the fast ion precession frequency was very small, fishbones would not present a problem. The toroidal mode numbers for these modes range from $n=1$ to $n=5$ and the modes generally appear when the $q(0)$ is inferred to be well above unity. 
As was the case with the TAE induced fast ion losses, burst of D-alpha light are also seen with the fishbone-induced fast ion losses during the $\mathrm{H}$-mode phase (the $\mathrm{H}$ mode transition in this shot is at about $0.26 \mathrm{~s}$ ). It is interesting, however, that before the H-mode transition, fishbone bursts (which in some cases are not accompanied by significant neutron drops) are correlated with D-alpha drops. A possible interpretation of this is that for a plasma near the $\mathrm{H}$-mode transition threshold can be transiently "pushed over" by the fishbone induced loss of fast ions [6].

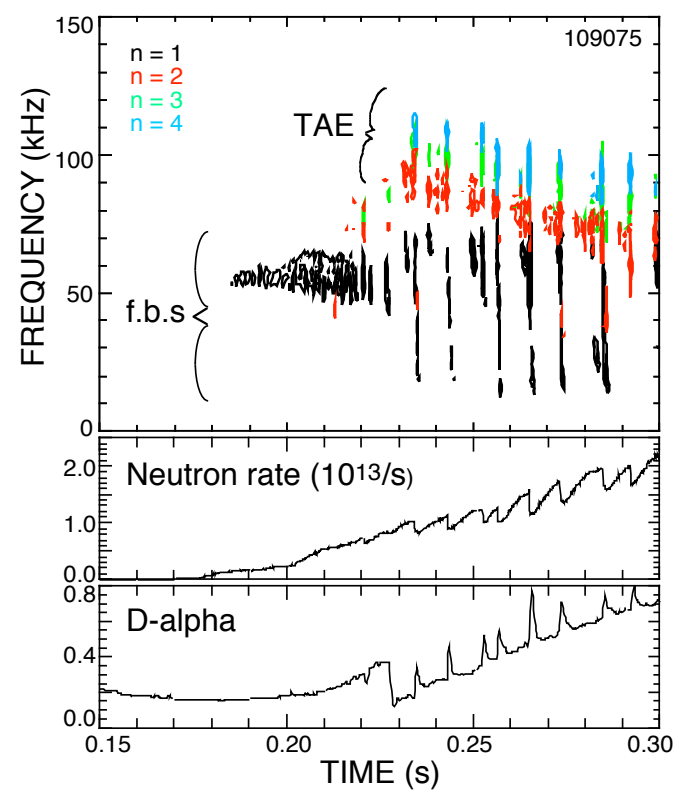

Fig. 4. Spectrogram of Mirnov coil showing bursting TAE and fishbone-like modes. Neutron rate drops are correlated with the bursts as well as spikes in the D-alpha light. The H-mode transition occurs at $0.227 \mathrm{~s}$

In many, if not most, instances, the TAE and fishbone bursts occur together as in Fig. 4. The fast ion losses, while again significant, do not appear substantially worse than for cases with TAE or fishbone modes alone. This example shows the typical behavior that the TAE bursts preceed the fishbone bursts, almost seeming to trigger the fishbones. This suggests a model that the TAE are driven primarily by fast ions in the plasma core, which when moved outward in minor radius excite fishbone modes. Conversely, the interaction between the TAE and the fishbone could be through changes in velocity space of the fast ion distribution.

Repetitive bursts of fast ion losses of the magnitude shown here can reduce the fast ion population in steady state by $30 \%$ to $50 \%$. This raises the threshold for ignition and poses problems for reactor first wall designs.

We are grateful to the NSTX team for supporting these experiments. This work supported by U.S. DOE Contract DEAC02-76CH03073.

[1] N N Gorelenkov, C Z Cheng, G Y Fu, S Kaye, R White, M V Gorelenkova, Phys. Plasmas 7 (2000) 1433.

[2] E.D. Fredrickson, N. Gorelenkov, C.Z. Cheng, et al., Phys. of Plasmas 9 (2002) 2069.

[3] M. Ono, et al., Nucl. Fusion 40 (2000) 557.

[4] E.D. Fredrickson, C. Z. Cheng, D. Darrow, et al. accepted Phys. of Plasmas.

[5] E Fredrickson, R White, L Chen, (submitted to Nuclear Fusion).

[6] S. Kaye, C E Bush, E Fredrickson, B LeBlanc, R Maingi, S Sabbagh, (submitted to Phys. of Plasmas). 


\section{External Distribution}

Plasma Research Laboratory, Australian National University, Australia

Professor I.R. Jones, Flinders University, Australia

Professor João Canalle, Instituto de Fisica DEQ/IF - UERJ, Brazil

Mr. Gerson O. Ludwig, Instituto Nacional de Pesquisas, Brazil

Dr. P.H. Sakanaka, Instituto Fisica, Brazil

The Librarian, Culham Laboratory, England

Mrs. S.A. Hutchinson, JET Library, England

Professor M.N. Bussac, Ecole Polytechnique, France

Librarian, Max-Planck-Institut für Plasmaphysik, Germany

Jolan Moldvai, Reports Library, Hungarian Academy of Sciences, Central Research Institute for Physics, Hungary

Dr. P. Kaw, Institute for Plasma Research, India

Ms. P.J. Pathak, Librarian, Institute for Plasma Research, India

Ms. Clelia De Palo, Associazione EURATOM-ENEA, Italy

Dr. G. Grosso, Instituto di Fisica del Plasma, Italy

Librarian, Naka Fusion Research Establishment, JAERI, Japan

Library, Laboratory for Complex Energy Processes, Institute for Advanced Study, Kyoto University, Japan

Research Information Center, National Institute for Fusion Science, Japan

Dr. O. Mitarai, Kyushu Tokai University, Japan

Dr. Jiangang Li, Institute of Plasma Physics, Chinese Academy of Sciences, People's Republic of China

Professor Yuping Huo, School of Physical Science and Technology, People's Republic of China

Library, Academia Sinica, Institute of Plasma Physics, People's Republic of China

Librarian, Institute of Physics, Chinese Academy of Sciences, People's Republic of China

Dr. S. Mirnov, TRINITI, Troitsk, Russian Federation, Russia

Dr. V.S. Strelkov, Kurchatov Institute, Russian Federation, Russia

Professor Peter Lukac, Katedra Fyziky Plazmy MFF UK, Mlynska dolina F-2, Komenskeho Univerzita, SK-842 15 Bratislava, Slovakia

Dr. G.S. Lee, Korea Basic Science Institute, South Korea

Institute for Plasma Research, University of Maryland, USA

Librarian, Fusion Energy Division, Oak Ridge National Laboratory, USA

Librarian, Institute of Fusion Studies, University of Texas, USA

Librarian, Magnetic Fusion Program, Lawrence Livermore National Laboratory, USA

Library, General Atomics, USA

Plasma Physics Group, Fusion Energy Research Program, University of California at San Diego, USA

Plasma Physics Library, Columbia University, USA

Alkesh Punjabi, Center for Fusion Research and Training, Hampton University, USA

Dr. W.M. Stacey, Fusion Research Center, Georgia Institute of Technology, USA

Dr. John Willis, U.S. Department of Energy, Office of Fusion Energy Sciences, USA

Mr. Paul H. Wright, Indianapolis, Indiana, USA 
The Princeton Plasma Physics Laboratory is operated by Princeton University under contract with the U.S. Department of Energy.

\author{
Information Services \\ Princeton Plasma Physics Laboratory \\ P.O. Box 451 \\ Princeton, NJ 08543
}

Phone: 609-243-2750

Fax: 609-243-2751

e-mail: pppl_info@pppl.gov

Internet Address: http://www.pppl.gov 